\title{
Perceptions of Obvious and Disruptive Climate Change: Community-Based Risk Assessment for Two Native Villages in Alaska
}

\author{
Jon Rosales ${ }^{1, *}$ and Jessica L. Chapman ${ }^{2}$ \\ 1 Environmental Studies, St. Lawrence University, 23 Romoda Drive, Canton, NY 13617, USA \\ 2 Math, Computer Science, and Statistics, St. Lawrence University, Canton, NY 13617, USA; \\ E-Mail: jchapman@stlawu.edu
}

* Author to whom correspondence should be addressed; E-Mail: jrosales@ stlawu.edu; Tel.: +1-315-229-5852; Fax: +1-315-229-5802.

Academic Editor: Iain Brown

Received: 13 June 2015 / Accepted: 9 October 2015 / Published: 16 October 2015

\begin{abstract}
This work operationalizes the determinants of climate change risk, exposure and vulnerability, through the perceptions held by Native hunters, fishers, and gatherers in Savoonga and Shaktoolik, Alaska. Informed by their skill, experience, and the traditional knowledge of their elders, hunters, fishers, and gatherers in these communities are astute observers of their environment and environmental change. A questionnaire is used to sort and rank their perceptions of the most obvious and disruptive elements of climate change as representations of exposure and vulnerability, respectively. Results represent the relative strength and significance of those perceptions of environmental change. In addition to other changes, storms are among the most obvious and disruptive impacts of climate change to respondents in both communities, while changes to sea ice tend to be more disruptive in Savoonga, a more ice-obligate culture, than Shaktoolik. Changes on the tundra are more obvious in Shaktoolik, but is the least disruptive category of change in both villages. Changes along the coast were both obvious and disruptive, albeit more so in Shaktoolik than Savoonga. The findings suggest that traditional ecological knowledge is a valuable source of information to access perceptions of risk, and develop climate risk management and adaptation plans. The questionnaire design and statistical methodology may be of interest to those working on community-based adaptation and risk assessment projects in high-risk, poor, and marginalized Native communities with small populations.
\end{abstract}


Keywords: risk perception; traditional ecological knowledge; climate change impacts; Arctic; adaptation

\section{Introduction}

Climate change is more pronounced in the Arctic than any other region, warming at twice the rate as the rest of the planet [1]. As a result, dramatic and sustained ecosystem change in the Pacific Arctic is being called the "new normal" [2] to contend with for decision makers and residents of this region. We cannot assume, however, all elements of climate change in this rapidly changing region are obvious and/or disruptive to its residents. Climate change risks are experienced unequally and are often location-specific [3] and indigenous communities in Alaska are particularly vulnerable [4]. It is therefore instructive for decision makers working on climate change adaptation to determine the perceptions of risk held by indigenous people living in this rapidly transforming region. It is also important to identify the particular adaptation needs of indigenous peoples and to assess climate change risk from their perspective.

Representing established terminology and interpretation of risk assessment, the Intergovernmental Panel on Climate Change (IPCC) finds that a location's determinants of risk are exposure and vulnerability [3]. Assuming all climatic changes are not equally hazardous, the terms "obvious" and "disruptive" are used to disaggregate the physical events to which villagers in Savoonga and Shaktoolik, Alaska are exposed and vulnerable in order to assess the relative risk of those physical events. Employing the terms obvious and disruptive for risk assessment also enables testing and quantitative verification of the relative confidence residents in these villages have in their observations of climatic change and to determine the relative risk those changes pose to the villages. This approach to risk analysis is grounded in the rich traditional ecological knowledge (TEK) held by hunters, fishers, and gatherers in these two villages.

\subsection{TEK of Climate Change}

While there is no universally accepted or entirely satisfying definition of TEK, it can generally be thought of as intergenerational knowledge that is drawn from interacting with the land. It is knowledge gained from a close experience with the surrounding environment [5,6] and social interaction with a locality [7]. TEK is usually transmitted orally [8]. However, TEK is more than a body of accumulated knowledge; it is an expression of a spiritual connection to the land [9], and is bound in the ethics of how to live in a relationship with nature [10]. TEK holders possess a personal frame of reference to assess change [11,12] that is contextual and not necessarily focused on cause-and-effect relationships [13-15]. TEK observations are not isolated accounts of change; they are coupled with and interpreted by what is important to the holders of this knowledge, such as tradition, sustenance, and security of person [14]. Their knowledge does not necessarily mirror the epistemology and timeframe of climate science [16], but the two forms of knowledge largely corroborate when it comes to identifying climatic changes in the Bering Sea area of western Alaska [17].

There is increased recognition of the value of TEK for environmental research $[5,16,18]$ and climate change research $[1,19,20]$, including how TEK can improve climate change adaptation $[1,3,9]$, and disaster preparedness and resilience [21]. TEK can be useful in identifying change at the local level and evaluating 
the significance of that change in the Arctic [5,22,23] and elsewhere [24]. Combining TEK and science co-produces knowledge and learning [25] and/or TEK can augment science [26], especially if the two are integrated [23] and understood as a complex, collaborative process [27-29]. Additionally, communities of TEK holders may offer models of how to adapt to climate change and alternative lifestyles [12], and may be as important for adaptation as climate science [24]. Therefore, many scholars have maintained for over a decade that TEK knowledge should be used in adaptation planning [20,26,30], especially for understanding local or regional impacts [31,32]. This work, however, must be done with the free, prior, and informed consent of the TEK holders and respective governing bodies, and with a full understanding that some knowledge is proprietary or comes with obligations when shared [9].

While TEK can and should be included in adaptation planning and risk assessment, a key question to be addressed is how best to include TEK in to these activities, especially in Native communities with small populations who may be reticent or unwilling to participate in academic investigations? One possible approach employed here is to sort and rank qualitative contextual information with quantitative questionnaire data. Combining the two approaches "scrutinize[s] traditional knowledge and its sources more carefully" [16] (p. 183). Ranking perceptions with the terms obvious and disruptive is used to verify the relative strength of those perceptions. Other scholars have found it "difficult or impossible" to assess the uncertainty of TEK [5] (p. 19) or that comparison of the two knowledge systems may reveal "irreconcilable differences" [33] (p. 270). While scholars should not assume homogeneity between TEK and science knowledge [24], TEK and science are not necessarily separate epistemologies, philosophies, or metaphysics [13] and can be combined to co-produce knowledge [25] if the survey allows it (see Methods below). Stemming from this grounding in TEK, two lines of inquiry and practice are used to investigate the perceptions of risk in Savoonga and Shaktoolik: community-based adaptation (CBA) and risk assessment.

\subsection{Community-Based Adaptation}

To its practitioners, CBA seeks to empower high-risk, poor, and marginalized communities that have contributed the least to climate change to plan for its impacts [34-36]. The IPCC concludes that the intent of CBA is "to foster active participation in collecting information that is rooted in the communities and enables affected people to participate in their own assessment of risk and identify responses that can enhance resilience by strengthening social-institutional measures including social relations" [3] (p. 321). In other words, CBA directly allows at risk people being affected by climate change to communicate how they perceive its risks and to determine adaptation practices [37]. While CBA focuses on the local context of climate change [3], it is also a political statement of the necessity, and value, of including community voices in their own development efforts [37]. An underlying assumption with CBA initiatives is that people know their local risks and vulnerabilities better than non-locals; in this case, residents of Savoonga and Shaktoolik are capable of determining what climatic changes are more obvious and disruptive to them than others. At the same time CBA recognizes that broader scaled knowledge, such as regional climate modeling, is also needed to get a full picture of vulnerabilities and risks [37]. For greater impact, CBA initiatives should be scaled-up and communicated to decision makers, and scaled-out by expanding to larger regions [34]. 
In addition, $\mathrm{CBA}$ is consistent with community-based disaster preparedness to form local coping and adaptation measures and to target root causes of vulnerability [38]. Since CBA engages the community in assessing hazards and vulnerabilities, and the community's capacity to adapt to these changes, CBA approaches are effective at assessing community risk [39].

CBA initiatives, however, have challenges: they are time, resource, and labor intensive [37,39]; local perspectives may not be taken seriously by decision makers and/or their perspectives may be distorted [38]; and it may be difficult to identify who speaks for the community and account for marginalized individuals in those communities [34]. A key challenge is that CBA initiatives are hard to scale up, to replicate, and transfer to other locations or broader regions [37,40]. In particular, with CBA initiatives, it has been hard to scale up qualitative findings [39].

\subsection{Risk Assessment}

Climate risk management, the incorporation of climate change information into decision making to reduce climate change risks [41], is an emerging field that begins with assessment of risk. Mercer et al. [6] develop a four-step process "for integrating indigenous and scientific knowledge" for risk reduction- community engagement, identification of vulnerabilities, identifying indigenous and scientific strategies for risk reduction, and developing an integrated strategy. Their second, identification of vulnerabilities, is the focus of this article.

Since scientific knowledge of climate change tends to be generalized, local knowledge is more effective in identifying particular risks, exposure, and vulnerability to climate change [42]. As explained above, TEK is an especially rich source of local knowledge that incorporates multigenerational knowledge, cultural structures for that knowledge, and spiritual components. Similarly, it must be recognized that perceptions of risk to climate change are not simply a reaction to being exposed to changes, but assessment of the disruptive capacity those changes pose to an individual in their particular cultural setting [15] and, more broadly, informed by a people's cultural-political history of "shared experiences, identity, values, and way of life" [43] (p. 56). The perception of climatic changes, therefore, is a useful starting point in a risk assessment process.

Extreme heat waves and floods receive the most public attention [44], and glacier or polar ice melt, unusual weather, and temperature changes are the three primary physical changes that lead people to believe that climate change is happening [45]. These changes have been documented in the Arctic [46,47] and in Alaska [48,49]. Due to these dramatic changes, Hansen et al. [50] surmise that climate change should have been obvious in Alaska in the late 1990s. That timeframe coincides with the awareness of climate changes documented for this article. For TEK holders, it should be noted, the perceptions of risk posed by climate change are not just physical changes, such as sea level rise and increased drought, but they are they are part of a more complex notion of self and "lifeworlds" [43].

In addition to being exposed to climatic changes, risk assessments require a determination of the susceptibility to be negatively impacted [3]. The concept disruptive is employed here to determine negative impact. Disruptive climate change in the Arctic is wide ranging. Climate change impacts to the cryosphere in the Arctic and its impact on flooding and erosion in coastal areas are well established [3]. Arctic indigenous residents are resilient, but their adaptive capacities are being challenged by the dramatic change and pace of change in that region $[8,51,52]$, changes perhaps as challenging as 
colonialism [53] to their ability to flourish and maintain their cultures, or what Whyte [54] calls their collective continuance. Communities practicing subsistence fishing and hunting are particularly impacted by climate change [55]. The latest IPCC assessment of climate change literature posits that the impacts of climate change on particularly rural and isolated indigenous peoples in the Arctic is significant and is expected to increase due to their exposure to climatic changes and vulnerabilities such as poverty, health services, and livelihoods that are closely linked to their environments [1]. There is "high confidence," they conclude, that climate change increasingly threatens traditional indigenous livelihoods in the Arctic [1] (p. 1583). Climatic changes in the Arctic are now serious enough to prompt governing bodies in the Arctic to ask scholars and scientists to identify thresholds of possible irreversible regime shifts [56].

In Alaska, sea and land-based ice is melting rapidly; temperatures are rising sharply; and drought, wildfires, and insect outbreaks are more common, all of which significantly impact Native communities there even with their long cultural experience of adapting to environmental change [49]. In Himes-Cornell and Kasperski's [55] index of climate change vulnerability in Alaska, of the three elements they use (exposure to climate change hazards, dependency on natural resources, and adaptive capacity), they identify exposure as the most critical element in determining vulnerability. The two communities in this study both score "highly exposed" and "highly dependent on natural resources" in their analysis of 315 Alaskan communities. The adaptive capacity of Savoonga is also rated high risk mainly due to their minimal commercial opportunities and per capita wealth, and they rate Shaktoolik's adaptive capacity as moderate based on the same criteria. (The resilience of these villages, however, is not solely a function of financial capacity. A strong subsistence culture and well-developed hunting, fishing, and gathering skills coupled with well-established kinship networks should also be factored in to adaptive capacities). Elsewhere, Shaktoolik has been identified by government agencies at the federal level $[57,58]$ and state level [59] as a high risk, imminently threatened village to climate change. Additional detail on the two communities is now given before a description of methods and results.

\section{Experimental Section}

\subsection{Study Sites}

This study is part of the ongoing Alaskans Sharing Indigenous Knowledge (AKSIK) project that since 2009 documents the impacts of climate change in Savoonga on St. Lawrence Island and Shaktoolik on the eastern shore of the Norton Sound (Figure 1). AKSIK is a science and advocacy project working solely in these two villages and communicates its findings via its website (http://AKSIK.org) mainly through the use of videos and short documentary films. Of upmost importance are the Village Coordinators who are Native residents in both villages who have a permanent presence in the community and serve as liaisons between investigators and the communities. AKSIK follows the ethic of free, prior, and informed consent established by the United Nations Declaration on the Rights of Indigenous Peoples [60]. Its work is carried out in consultation with and with the consent of the tribal councils, the governing body of the tribe in both villages established with the Indian Reorganization Act of 1934. AKSIK investigators have met with tribal and city boards, held community meetings, and met with individuals since 2010, and 
continue to return to the villages. Frequent visits help build trust, reaffirm commitment, and offer sequential encounters with TEK holders there to make sure information is correctly documented.

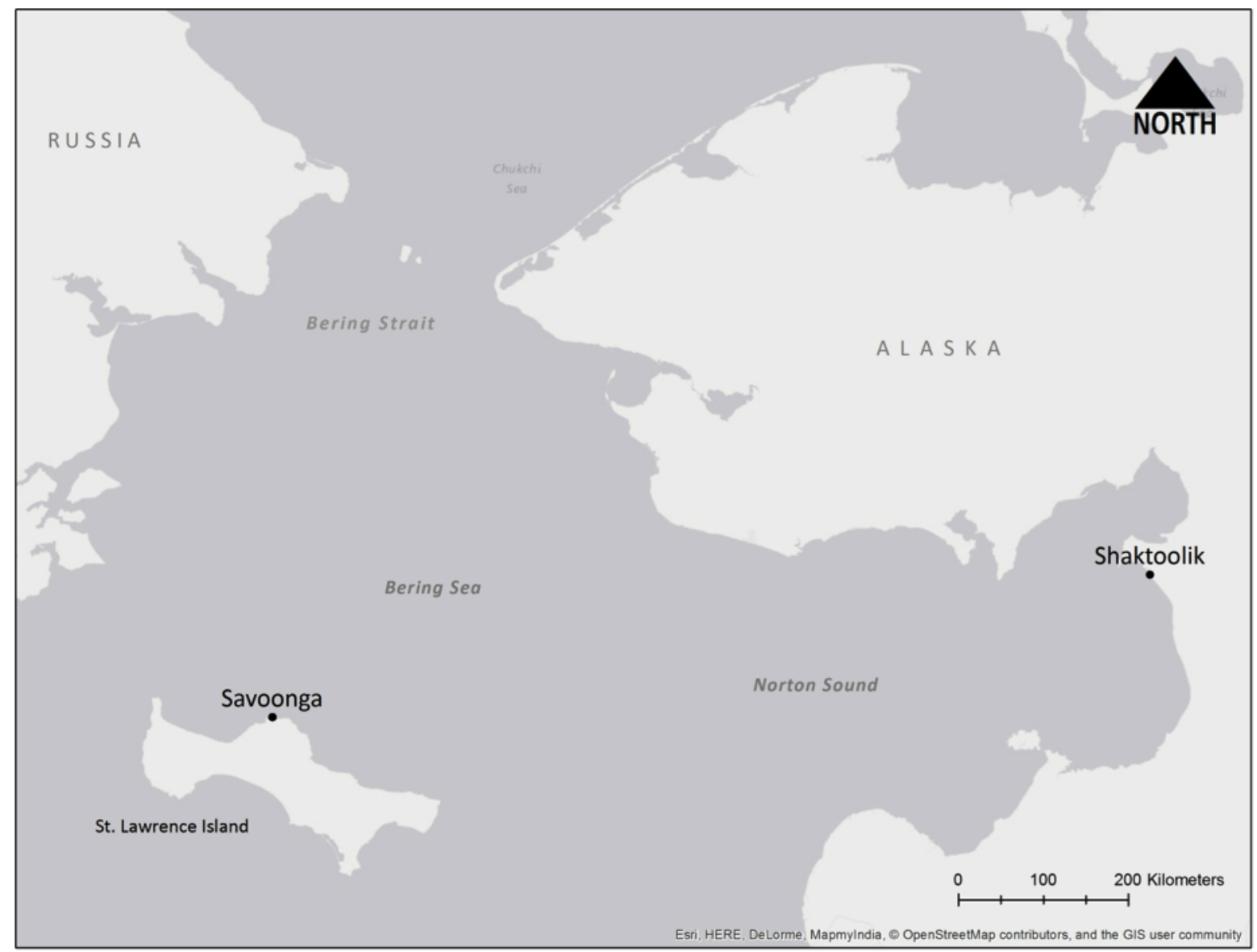

Figure 1. Study sites in the Bering Sea area of western Alaska, USA.

Both villages are rich in traditional ecological knowledge (TEK). As in other Native communities in the Arctic [15] and around the world [8], subsistence hunting, fishing, and gathering are widely practiced by residents of both villages, and to a large degree determine their identity and culture. Residents of these two villages practice subsistence activities throughout the year [17], bringing them in close contact with their environment. Both communities are what Fall et al. [61] call "a mixed subsistence/cash economy" (p. 274), consuming traditional foods harvested from the land and market commodities such as gasoline, canned and box foods, and snow machines.

The Native Village of Savoonga is a federally recognized indigenous tribe. This Siberian Yupik village has $94 \%$ of its population of 671 identifying themselves as Alaska Native [62]. Savoonga's subsistence culture is drawn from hunting bowhead whales (Balaena mysticetus), walrus (Odobenus rosmarus), and seals, and gathering murre (Uria aalge) eggs, various tundra greens, and salmon berries (Rubus spectabilis) [17]. Increasingly, residents fish commercially for halibut (Hippoglossus stenolepis) through the Norton Sound Economic Development Corporation and manage a reindeer (Rangifer tarandus) herd on the east side of the island for commercial sale. 
The Native Village of Shaktoolik is also a federally recognized indigenous tribe with $96 \%$ of its 251 residents identifying themselves as Alaska Native [62]. The culture of Shaktoolik is greatly drawn from its subsistence activities such as hunting for caribou (Rangifer tarandus), seals, and waterfowl, fishing for trout and Arctic grayling (Thymallus arcticus), and gathering sea peaches (Halocynthia aurantium), Alaska wild rhubarb (Polygonum alaskanum), blueberries (Vaccinium corymbosum), and blackberries (Rubus fruticosus) [17]. Through the Norton Sound Economic Development Corporation, Shaktoolik residents fish commercially for Alaska pollock (Theragra chalcogramma) and Pacific herring (Clupea pallasii), and harvest red king crab (Paralithodes camtschaticus).

These activities make residents of Savoonga and Shaktoolik astute observers of environmental change with hunters, fishers, and gatherers spending a great deal of time in the field, watching the weather, preparing to go out, and processing the foods they harvest. In order to be successful, and to remain safe in hazardous Arctic conditions, these activities require close observation of the physical environment, surrounding ecological systems, and biological organisms. Subsistence cultures and villages like Savoonga and Shaktoolik endure because of their abundant knowledge of their local environment, and are aided by strong traditions of elders passing on traditional knowledge, and by strong ties to clans and their networks of sharing resources and catch.

\subsection{Methods}

Consistent with the IPCC's assessment that qualitative and quantitative assessments are needed to "capture the full complexity" of climate change risk assessment [3] (p. 67) and informed by the lines of inquiry outlined above, a questionnaire, and follow-up communication with respondents is used, to gather, sort, and rank qualitative information to assess climate change risk in Savoonga and Shaktoolik. To determine exposure, residents were asked in both communities to identify which elements of climate change are most obvious. The term "obvious" identifies the degree to which respondents experience and perceive climatic changes in order to ascertain what elements of change affect them in their location, as opposed to commenting on climatic changes in general. Vulnerability is determined by asking them about which of those same elements are the most disruptive, that is, what elements most negatively interfere with their lives and livelihoods. The questionnaire (see Supplemental Material) was built from previous AKSIK work published in Ignatowski and Rosales [17] where, based on interviews in 2010 and 2011, elements of climate change witnessed over the last 20 years in Savoonga and Shaktoolik are identified. The questionnaire was administered to 14 residents of Savoonga and Shaktoolik in 2012. Respondents were asked to respond to questions in five broad categories - changes along the coast, to the weather, sea ice, storms, and on the tundra (see Supplemental Material). The pool of respondents to draw from was limited by the small population sizes in the villages, time constraints (questionnaire session lasted up to $1.5 \mathrm{~h}$ ), and willingness to participate. AKSIK Village Coordinators selected seven willing respondents from each village for their knowledge of environmental change, experience observing environmental conditions, and/or perceived role as elders. These conditions put significant constraints on the pool of qualified respondents. In Shaktoolik, for example, there are only 59 residents over the age of 45 [63] who may be considered an elder, perhaps half of those who had extensive TEK, and even fewer who would make the time and be willing to participate in an unfamiliar activity such as answering a questionnaire and being recorded. 
On average, the respondents in Shaktoolik were 53 years old (range 36-62 years), while the respondents in Savoonga had an average age of 62 years (range 47-79 years). The respondents from Shaktoolik included four males and three females, while all respondents from Savoonga were male; women in Savoonga were unwilling to participate yielding to male hunters as authorities on environmental change. Because of the small sample sizes, inferential statistical methods were not used; a descriptive analysis of the questionnaire results is presented instead.

Consent to publish the results of this work was granted by the Tribal Council of Savoonga in 2013 and Shaktoolik in 2014, and conversations with our Village Coordinators continued throughout 2015 to construct the context of our results (see Results below).

\subsubsection{Obvious Changes}

Respondents held a modified hemming tool used for sewing, a device familiar to them (Figure 2), to rank each question from 0 to 10 as the elements of climate change were read to them. Respondents were given an example of whether it was obvious that it was raining outside or not in order to understand the scale: 10 means yes they could see it is raining and 0 means no it is not raining. Questionnaire sessions were audio recorded as respondents were also asked to "think out loud" in order to understand the context and specific explanations of their responses. This qualitative information was retained in digital format, pegged to each question.

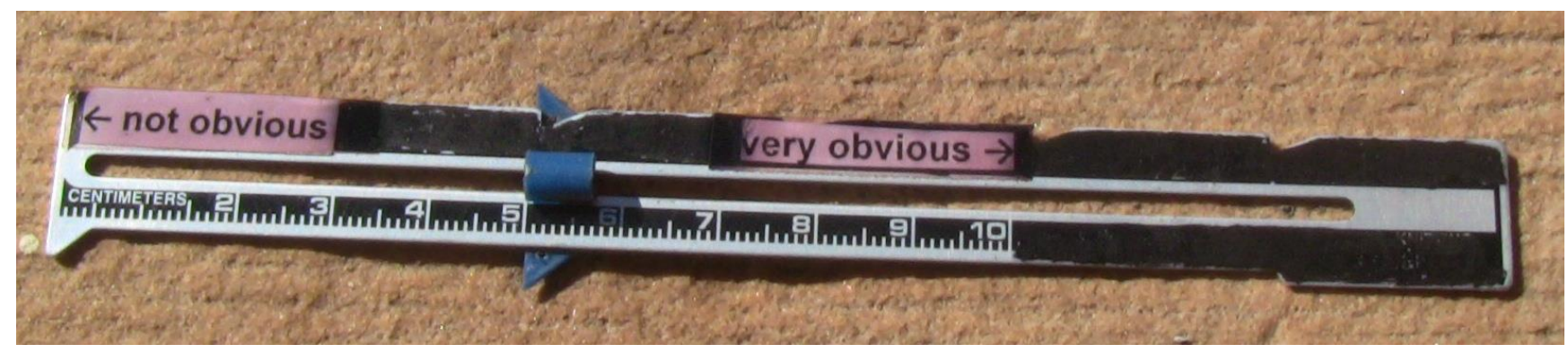

Figure 2. To indicate their responses, respondents used a modified hemming tool, a device familiar to them that helped them feel at ease.

Occasional responses are missing for some elements of climate change where respondents chose not to answer. Missing responses were infrequent (six questions are missing from a single response, and one question is missing from two responses) and can be interpreted as instances where the respondent did not feel they had enough knowledge to rate the obviousness of a particular element of climate change; for example, someone who does not frequently travel across sea ice may not feel knowledgeable enough to rate types of change related to sea ice.

Respondent rankings were classified as "Least," "Moderate," or "Most" obvious to determine the relative strength of their perceptions. Converting the raw rankings to categorical classifications is problematic because the ratings assigned by an individual are shaped by that individual's experiences and frame of reference. For example, an " 8 " to one individual may be a " 5 " to someone else. In other words, rankings within an individual are comparable, but ranking across individuals are not. Thus, to determine the categorical classifications, differences due to individuals were first taken into account. This was done by determining the average rating given by each individual and then subtracting their 
average rating from each of their ratings to create scores centered around zero for each individual. The centered scores thus represent how the obviousness of a particular element of change differs from the "average obviousness" of each respondent; positive values indicate elements that are more obvious than the average element, while negative values correspond to elements that are less obvious than the average. The centered rankings across all individuals and categories were then combined together and divided into thirds, with the lowest third of centered ratings (those below -0.111) being classified as least obvious, the middle third being classified as moderately obvious, and the highest third (those above 0.786 ) being classified as most obvious. It should be noted that elements of change classified as "least" obvious are not necessarily non-obvious; they are simply, relatively speaking, less obvious to the respondent than other elements of change.

\subsubsection{Disruptive Changes}

After completing the ranking exercise for obvious climate change, respondents in each village were given chips with the broad categories of change (weather, seasons, storms, sea ice melt, sea ice types, rain, winds, coastline, erosion, tundra, and permafrost) printed on them and asked to place the chips in three groups, "High," "Medium," and "Low," pertaining to how disruptive those changes have been to them. Rain again was used as an example to get used to the exercise, this time asking respondents to rank how more rain in the winter disrupts their lives.

As above, to reduce the number of categories considered in the analysis, categories were combined into those pertaining to the coast, ice, storms, tundra, or weather. Once the ranking had been achieved, respondents were asked to comment on the changes they ranked "High." Specifically, they were asked the following questions: How do these affect you being able to provide for your family? How do these affect sharing of resources? How do these affect the role of elders in the village? How do these affect young people in the village? Finally, are there any benefits to these changes? As before, their responses were audio recorded and digitally pegged to the questions. The statistical software R [64] and its vcd (Visualizing Categorical Data) package [65] were used to create mosaic plots to summarize results (Figure 3).

\section{Results}

\subsection{Ratings of Climatic Change Categories}

Figure 3a summarizes the questionnaire results, regarding the obviousness of elements of change, for the seven respondents from Shaktoolik. Changes in storms tended to be most obvious to the respondents from Shaktoolik, with more than $80 \%$ of the responses pertaining to storms classified as highly obvious, followed by coastal changes, with more than $50 \%$ of the responses related to storms rated as highly obvious. Changes in weather tend to be moderately obvious more often than any other category (roughly $1 / 3$ were classified as moderate), while changes in ice tend to be least obvious in Shaktoolik, with about $50 \%$ of responses classified as low in obviousness. 


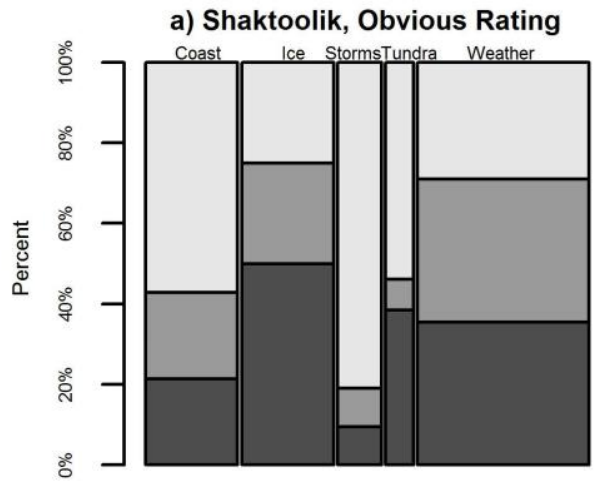

c) Savoonga, Obvious Rating

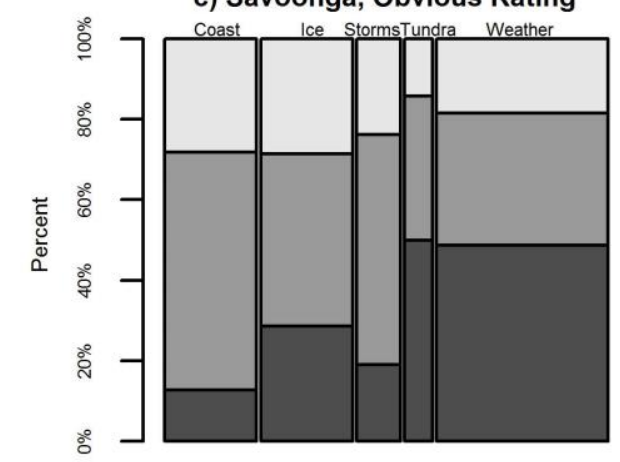

b) Shaktoolik, Disruptive Rating

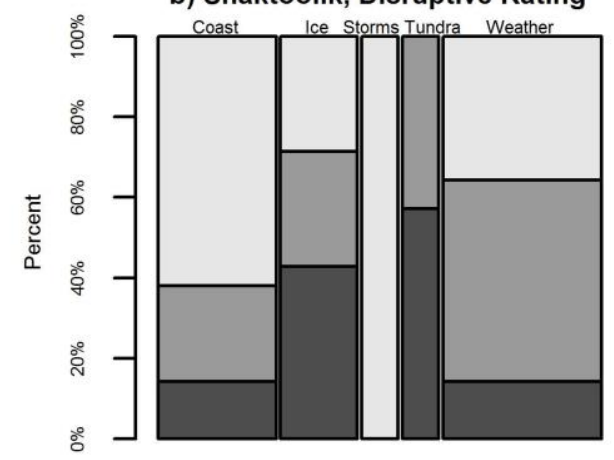

d) Savoonga, Disruptive Rating

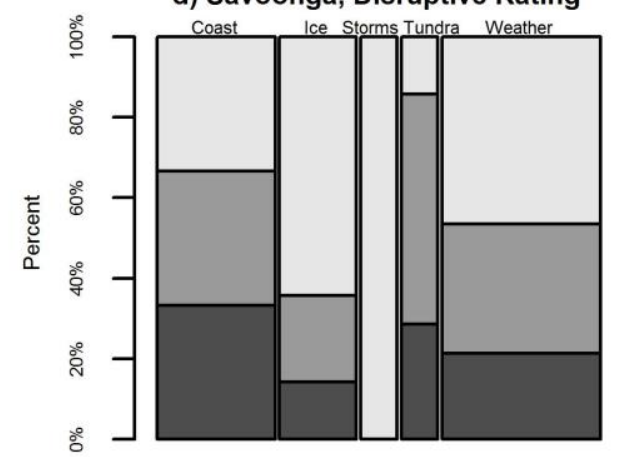

Figure 3. (a) Mosaic plots examining the relationship between categories and obviousness (b) rating and disruptiveness (c,d) rating for Shaktoolik and Savoonga. Widths of the broad categories correspond to the number of specific climate change-related changes in the broader category.

The questionnaire results on elements of change considered disruptive to respondents in Shaktoolik are summarized in Figure 3b. Changes in storms tended to be most disruptive, with all individuals rating them as most disruptive. Changes in the tundra tend to be least disruptive, with no individuals rating them as highly disruptive. Changes to both coast and weather tended to be more disruptive than not, with less than $20 \%$ of the responses for each classified as least disruptive.

It is clear that changes that are obvious to the respondents in Shaktoolik are not necessarily disruptive (Figure 3a compared to Figure 3b). Changes in storms were rated as most obvious and most disruptive with coastal changes ranked as the second highest in both obviousness and disruptiveness. After that, the order of the categories changes, with changes to the tundra being somewhat highly obvious, but no one considered those changes to be highly disruptive.

Figure $3 \mathrm{c}$ summarizes the responses on the obvious of the elements of change for the seven respondents from Savoonga. Changes in ice and coastal changes tend to be most obvious at similar rates, with nearly $30 \%$ of the responses for each classified as highly obvious, but the latter tend to be more moderately obvious, with fewer low obviousness ratings (only about 10\%), than any other change category. Changes in weather and tundra tend to be least obvious of all categories in Savoonga, with nearly $50 \%$ of responses on related elements being low in obviousness.

Finally, Savoonga respondents consistently rated changes related to storms as disruptive (Figure 3d). Changes related to ice, weather, and tundra tended to be more disruptive than not, with only a small 
percentage of responses in these areas classified as "least" disruptive; the majority of responses pertaining to ice were classified as highly disruptive, about half of the responses related to weather were rated as highly disruptive, and the majority of the changes impacting the tundra were rated as moderately disruptive. The ratings about the disruptiveness of changes impacting the coast were fairly evenly split between the three levels. As seen in the responses from Shaktoolik, the changes that were rated as most obvious in Savoonga were not necessarily the rated as the most disruptive.

\subsection{Description of Sorted Categories}

Guided by the sorting and ranking of quantitative questionnaire data, qualitative information from the questionnaire sessions provides context for the categories discussed above.

\subsubsection{Storms}

It is obvious to TEK holders in both villages that storms have changed over the last 20 years, in fact the more intense storms have, as one respondent from Shaktoolik put it, "Increased awareness of change in general." This commonality between the two villages is not surprising since the large fall storms encompass the entire Bering Sea region and these two villages are only 280 miles apart. In particular, an increase in storm intensity is highly obvious in Shaktoolik and moderately obvious in Savoonga, but in both villages larger fall storms are increasingly disruptive to their lives.

It is more obvious in Shaktoolik, in particular, than in Savoonga that people are scared of the large fall storms. This is consistent with various federal and state level investigations that find Shaktoolik particularly vulnerable to flooding and erosion that accompanies large storms $[57,66,67]$. The village is located on the coast on a narrow spit about $7.5 \mathrm{~m}$ above the average lower low water tidal heights [68]. Storm surges from recent large fall storms in 2005, 2009, 2011, and 2013 have increasingly neared the village, explaining why they state that storms are stronger. The November 2011 storm produced peak storm surges of over $7.5 \mathrm{~m}$ in the area [66]. The large storm in November 2013 drove driftwood into village buildings. When coinciding with high tide, the entire outwash plain on the opposite side of the spit fills with water during the storms, flooding infrastructure and nearing the houses. There is no evacuation road or means, by boat or airplane, to evacuate people during these storms. People are now scared that the crashing waves, littered with large driftwood, will destroy their homes and submerge the village. The village has decided to do all they can in the absence of state and federal funding. The village is doing CBA; they identified a need and developed a response [3]. Tribal and city government along with the Native Corporation coordinated in 2014 to construct a protective berm in front of the village to guard against storm surge. Piecing grant money together, the village managed to secure two aging dump trucks to haul gravel from a source roughly four kilometers down the coast to cover and back fill the berm (Figure 4a). The village used any possible material, including derelict front-end loaders that might hold back the water (Figure 4b). Whether the berm will hold or not is not known. One respondent said, "People are calling [the berm] a beaver dam" because of the driftwood underneath. This person then added, "but beaver dams are durable and they work." 


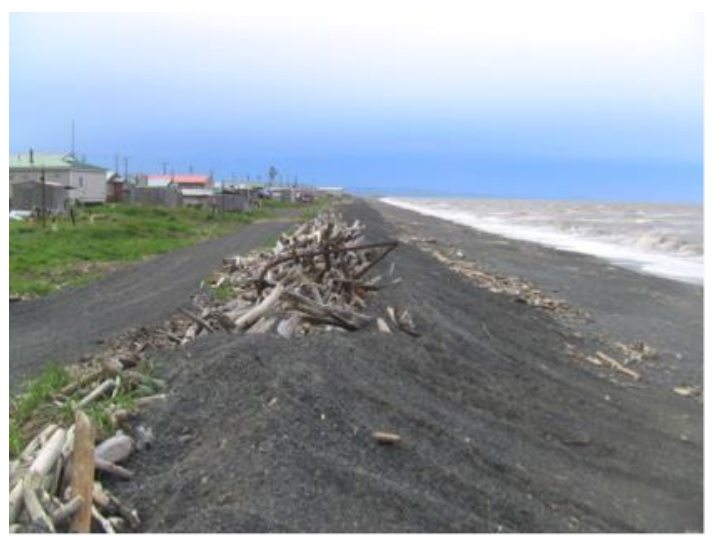

(a)

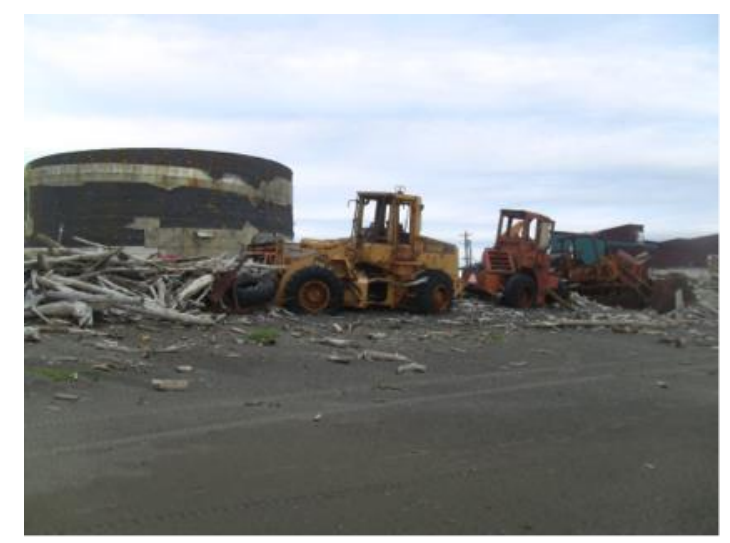

(b)

Figure 4. (a) Berm construction efforts in Shaktoolik include piling up driftwood, and (b) other material including scrap front-end loaders, in an effort to construct the protective berm. Work continues to cover and backfill the berm with gravel. Photo credit: Jon Rosales.

While increased storm intensity is moderately obvious in Savoonga the storms are also disruptive to the residents there. While storm surge is not as critical a threat in Savoonga, which is situated higher above sea level and less exposed, respondents there also mentioned that they are scared of the fall storms, especially the impact of high winds. The same large storms that hit Shaktoolik also disrupted fall hunts in Savoonga, knocked out power, high winds travelled down exhaust pipes blowing out oil heaters, damaged houses, and caused fear with flying debris amongst the $160 \mathrm{~km} / \mathrm{h}$ winds.

\subsubsection{Ice}

A category of change that shows diverging perceptions between the two villages is ice. Changes to the sea ice around Savoonga are more obvious and disruptive than in Shaktoolik; one Savoonga respondent acknowledged, "We are sea-ice dependent." Respondents in Savoonga explained that the sea ice goes out earlier and more quickly in the spring now than it did 20 years ago. Since much of the diet in Savoonga is derived from walrus and seals, finding the edge of the sea ice where these mammals exit the water is crucial to hunting success. An earlier spring break up of sea ice increasingly overlaps with their whaling season, which is done on the south side of the island, and hunters expressed concern over being able to return to the north side in time to go walrus hunting. There used to be a month or so in April of good hunting but now it is a matter of days for both whales and walrus. With sea ice retreating faster, hunters in Savoonga also expressed their difficulty in finding it and having to travel out over 160 $\mathrm{km}$ from the village to find the sea ice. One respondent said, "Polar bears are also having a hard time finding the ice" and are increasingly seen stranded on the island. An adaptation measure they have taken is that hunters now use satellite technology to connect to the National Weather Service to help locate ice flows. When combined with their TEK, the scientific instrumental data results in an adaptation risk reduction strategy in Savoonga, as suggested in Mercer et al. [6]. This technique, however, bypasses the traditional sources of knowledge of the elders leaving them wondering about their usefulness. However, even with technological assistance, hunters are adapting by fishing for halibut to supplement their diets and income with the establishment of a modest commercial fishing processing plant. 
Hunters also express concern over their safety, fuel costs, and how they increasingly are leaving children at home so that they can focus on successful hunts with the fewer and fewer hunting forays. One respondent said, "They now go out at their own risk... Hunting is less safe [now]." Respondents also explained that the sea ice is not as thick and old as it used to be as one respondent said, "We don't see that multi-year ice anymore." Thick shorefast ice, for example, is needed to access game and support the weight of large marine mammals. It is increasingly difficult, for example, for whalers in Savoonga to haul out large bowhead whales (Balaena mysticetus) that can weigh over 40 tons on thinner ice. As a result, they are now going after smaller whales. Some residents of Savoonga are also turning to reindeer (Rangifer tarandus) meat to sell wholesale and within the village, and adding Pacific halibut (Hippoglossus stenolepis) to their diet to supplement the decline in marine mammals. Less preferred seal meat (ringed, spotted, and ribbon seals), common murre (Uria aalge) meat, and fish like Dolly Varden trout (Salvelinus malma) are now supplementing their diet as well.

\subsubsection{Coast}

Changes to the coastline are obvious in both locations. Of particular concern with erosion in Shaktoolik is their village freshwater source. Shaktoolik pumps water to the village municipal water system from about two kilometers down the coast where the Shaktoolik River starts to bend away from the coast, a place called First Bend. The coast has been eroding significantly there leaving less land between their freshwater source and the ocean. Residents often go out to First Bend to pace off the distance between the ocean and the river. The distance is now 25 paces, as several respondents mentioned, and respondents told us they remember when the distance was a $0.5 \mathrm{~km}$ or so in their youth. At present, there is no other freshwater source for the village and no easy adaptation options to elongate the pipe up river beyond where salt water may intrude. Along with the threat of increased storm intensity, respondents in Shaktoolik perceive the threat of coastal erosion compromising drinking water system as a key vulnerability and puts them at high risk to climate change [59]. The drinking water supply is not threatened by coastal erosion in Savoonga.

Change in the angle of the coastline is also obvious in Shaktoolik with respondents stating that the beach has become noticeably steepened, as one respondent said as she moved her hand across her body parallel to the ground and looking out the window at the beach, "It used to be so flat." The size of the grains of sand in front of Shaktoolik are smaller than 20 years ago as the larger grains and stones have moved southeast they say. Many villagers walk and/or drive on the beach as a form of recreation and travel to hunting, fishing, and gathering sites. Savoonga respondents also told us their beaches have eroded with bedrock showing in parts and beaches becoming narrower making it difficult to moor and unload their boats, and haul in whales. How obvious a category of change is in these villages, therefore, depends in part on how often their activities put them in proximity to the change. In both locations, villagers now travel inland where the beaches are too narrow or sloped, or they abandon those areas where access is no longer available by all-terrain vehicle.

\subsubsection{Weather}

Accurately interpreting the weather is well documented by anthropologists as a crucial skill for hunting, fishing, and gathering success, cultural standing, and survival in Savoonga [69] and in mainland 
indigenous cultures, like Shaktoolik, in Alaska [70]. Many respondents and subsequent communications have told us that the weather is not as predictable as it used to be, affecting their subsistence activities. Respondents in both villages tell us about how the timing and duration of temperatures and rain is less predictable. Summers, they say, are now longer and fall weather lasts later in the year. Winters are shorter than they used to be 20 years ago, and long stretches of calm, clear weather is now rare. These changes also affect plant and animal phenology, they tell us, with marine mammal and bird migrations, and plant or berry harvest times being less predictable. Of particular disruption are the changes to marine mammal migrations in Savoonga and fish migrations in Shaktoolik. More frequent and ill-timed rain makes it difficult to dry fish and seal meat. "More rain in the late summer," however, "leads to larger berries," one respondent said, another said "larger plants, that's a bonus." Although not as confident in these facts, villagers say it rains more frequently in the winter and for more days in a row.

Of particular importance, however, are changes to wind patterns. These changes are obvious and disruptive to residents of Savoonga, particularly the hunters who go out on the ocean. Like elsewhere in the Arctic [30], hunting by boat on the ocean depends on being able to read and predict the wind for safety and hunting success. Elders help in this regard by monitoring weather conditions on a daily basis and communicating this knowledge to younger hunters. In Savoonga, much of this communication transpires at the grocery store where elders sit, drink coffee, and talk with younger hunters who venture in to interact with them about, among other things, hunting strategies. They also communicate over citizens band radio and, increasingly, cell phone. A holistic, culturally rich and defined tradition of watching the weather, including wind patterns, in Savoonga is aided by an expansive and precise vocabulary about weather and ice conditions [14,69]. Strategic and clever techniques, such as looking at cloud movement, ripples on the ocean surface, or the formation of drifting snow, passed through generations, creates a complex epistemological understanding of wind. It is now obvious in Savoonga that those abilities are not as reliable as before the 1990s when wind patterns, they say, began to change. The prevailing wind direction has changed from N-NE wind in the winter to long bouts of warm, rainy S-SE winds that pushes shorefast ice out and melts snow and ice. Wind patterns now are generally less consistent, changing quickly, and are less predictable, again outstripping the capacity of the elders to help younger hunters. An elder in Savoonga stated that they feel "like children" compared to their elders in being able to predict the weather. A younger hunter said that the elders "are paying more attention" and "are more engaged" due to the increasingly perilous hunting conditions. As Krupnik and Jolly suggest, these perceptions held by the respondents are assessments of change filtered through their particular cultural setting [15].

\subsubsection{Tundra}

Changes to the tundra were less obvious than other categories and the least disruptive category of change to respondents in both villages. Tundra sloughing off into the rivers when travelling outside of Shaktoolik is the most obvious element of climate change on the tundra in this region and it is readily apparent when traveling up the rivers. The tundra sloughing into the rivers is more obvious in Shaktoolik since the village is located at the mouth of two rivers and much of their subsistence and recreational activities involves boating up these rivers. Respondents were able to identify the precise stretches of river where this is happening. The main cause is most likely the visible permafrost melting that 
destabilizes riverbanks, an observation that is consistent with other scientific studies [71]. In Shaktoolik, with expansive view of the landscape, frequent travel on the tundra for hunting birds and caribou (Rangifer tarandus), and use of the Iditarod Trail for transportation, the change on the tundra is more frequently encountered. They tell say that there is less snow on the tundra, which affects salmon berry (Rubus spectabilis) size, and harvest amounts. The rivers are smaller near Savoonga and are encountered frequently, but mainly in brief encounters when crossing on four wheelers, which may explain why permafrost melt on riverbanks is less noticeable there. In both locations, respondents stated that lakes on the tundra are disappearing more frequently, again perhaps from melting permafrost underneath, and that there is less snow on the tundra affecting winter travel by snow machine and disrupting access to hunting sites. These changes were not stated as disruptive in Shaktoolik and only moderately disruptive in Savoonga, mainly as hunting waterfowl locations are changing. On a positive note, dried up lakes make good, flat trails for easier travel on St. Lawrence Island.

\section{Discussion}

Consistent with the literature encouraging the inclusion of TEK and adaptation planning [1,3,20,26,30], the TEK presented in this paper is useful for adaptation managers in need of documented local impacts for risk assessment. Documenting the exposure and vulnerability in just two locations in the Bering Sea area of Alaska cannot replace village-specific investigations of other villages in the region, but may serve as a baseline for other villages in the region. The TEK presented here, more importantly, assesses the significance of those changes $[5,22,23]$ in the impacted communities by sorting and ranking responses in a way that can be useful to managers to prioritize adaptation strategies through a gradient of local perceptions. As in other investigations [11-15], the TEK and local observations from Savoonga and Shaktoolik are not impartial observations, but are framed by particular cultural settings including hunting, fishing, and gathering experience; tribal traditions; and varying concerns for security and perceptions of risk. For example, hunters in Savoonga, like their Siberian Yupik ancestors, expect to travel up to $30 \mathrm{~km}$ from land to find bowhead whales (Balaena mysticetus), walrus (Odobenus rosmarus), and seals, and have developed traditions such as communication at hunting camp between captains and crew before launching, and communication with elders and family at home via citizens band radio as precautionary measures in case of emergency. When younger hunters are out hunting near the ice pack, elder hunters, who can no longer hunt, listen carefully to hunters communicating via radio for news of a strike, for keeping track of boats and crew, and to launch emergency rescues is necessary. To experienced hunters, what constitutes dangerous conditions is tempered from over- and underreaction to changing climatic conditions by experience. Their perceptions of risk, in other words, are specific to their experience, traditions, and what they know. For these reasons, we conclude that TEK is an appropriate and valuable source of information to access perceptions of risk, and develop accurate climate risk management and adaption plans.

While there are a myriad of ways to assess exposure and vulnerability, the method employed here may be of particular interest to those practitioners working on CBA projects in indigenous villages and who wish to identify climate change risk as it is perceived by the people being affected. This approach is consistent with CBA practitioners who seek to empower high-risk, poor, and marginalized to participate in their own assessment and communicate how they perceive climate change risks $[3,34,35,39]$. Savoonga 
and Shaktoolik are poor and marginalized indigenous villages, and Shaktoolik has the additional pressure of being a high-risk community to the impacts of climate change [59]. The intention of the AKSIK project from the outset was to work in rural, isolated Native villages because they are marginalized communities that were significantly affected by climate change, and expected to worsen [1], and yet were not receiving much attention by decision makers.

This research is similarly challenged by what others doing CBA research have identified. Scaling the findings up to other communities is especially difficult [34], and in particular it is difficult to scale-up qualitative findings [39]. While the findings differ between Savoonga and Shaktoolik, there is enough commonality between the two villages on the negative impacts of increased storm intensity and their negative effects to assume other villages in the Bering Strait region are equally vulnerable if exposure to these events exists [55]. The increasingly unpredictable weather patterns for other subsistence communities may be similarly exposed and vulnerable. Other ice-obligate communities in the region may also be impacted.

Our questionnaire design, however, can be scaled-up and replicated in other communities in Alaska and perhaps beyond. With more than 170 rural communities in Alaska experiencing erosion [58] and over 30 "imminently threatened" by erosion and flooding [57], decision makers in Alaska and elsewhere in the Arctic may be interested in our culturally appropriate survey instrument that enables decision makers to prioritize climate change adaptation plans to focus on what specific impacts of climate change in each community. As other investigators have noted about CBA projects [37,39], working in these remote villages is time and labor intensive, and costly. Decision makers may choose to train regional entities working on community and economic development to conduct these assessments.

Finally, the CBA approach has difficulty ensuring that community members who participate in the research speak for the community as a whole [35]. Similarly, the findings here pertain to the people who responded to the questionnaire, not the communities as a whole. This challenge reveals the limited capacity for recruiting large sample sizes for questionnaires or surveys in small villages. The quantitative methodology was limited by the sample size; a larger sample size is more preferable if possible so that researchers could utilize inferential statistical methods or more sophisticated statistical models. That being said, many of the villages in Alaska being impacted by climate change have very small populations. In fact, 55\% of the villages identified by the General Accounting Office in 2009 as "imminently threatened" with flooding and erosion [57] have populations less than 400 people [72]. More generally, 75\% of the settlements in Alaska designated as "places" where census data are kept have populations smaller than Savoonga and 51\% have populations smaller than Shaktoolik in 2013 [72]. Similar statistical constraints may confront researchers and decision makers working in these communities and in need of a survey methodology as the one used here.

The qualitative and contextual information compiled in this study also has broader significance. It identifies for others living outside of the Arctic what Native residents there are witnessing and foretells the characteristics of climate change that become apparent and disruptive first, and, as Salick and Ross [73] surmise about traditional peoples and climate change, "may help society at large to cope with the impending changes" (p. 137). 


\section{Acknowledgments}

The hunters, fishers, and gatherers in Savoonga and Shaktoolik are the knowledge-bearers of this work. While they have agreed to remain anonymous, we acknowledge them as fellow scholars and scientists of this work. In addition, we could not have carried out this work without the guidance and coordination of P. Pungowiyi in Savoonga and C. Sookiayak in Shaktoolik, our village coordinators for the AKSIK project. M. Larson generated Figure 1. Thank you all.

\section{Author Contributions}

Jon Rosales conceived and designed the experiments; Jon Rosales performed the experiments; Jessica Chapman analyzed the data; Jessica Chapman contributed analysis tools; Jon Rosales wrote the paper with Jessica Chapman providing first draft of Experimental Section and Results; and Jon Rosales and Jessica Chapman edited the manuscript.

\section{Conflicts of Interest}

The authors declare no conflict of interest.

\section{References}

1. IPCC (Intergovernmental Panel on Climate Change). Climate Change 2014: Impacts, Adaptation, and Vulnerability. Contribution of Working Group II to the Fifth Assessment Report of the Intergovernmental Panel on Climate Change; Field, C.B., Barros, V.R., Dokken, D.J., Mach, K.J., Mastrandrea, M.D., Bilir, T.E., Chatterjee, M., Ebi, K.L., Estrada, Y.O., Genova, R.C., et al., Eds.; Cambridge University Press: Cambridge, England, 2014.

2. Moore, S.E; Stabeno, P.J. Synthesis of Arctic Research (SOAR) in marine ecosystems of the Pacific Arctic. Prog. Oceonogr. 2015, 136, 1-11.

3. IPCC (Intergovernmental Panel on Climate Change). Managing the Risks of Extreme Events and Disasters to Advance Climate Change Adaptation. A Special Report of the Working Groups I and II of the Intergovernmental Panel on Climate Change; Field, C.B., Barros, V., Stocker, T.F., Qin, D., Docken, D.J., Ebi, K.L., Mastrandea, M.D., Mach, K.J., Plattner, G.K., Allen, S.K., et al., Eds.; Cambridge University Press: Cambridge, England, 2012.

4. Chapin, F.S, III; Trainor, S.F.; Cochran, P.; Huntington, H.; Markon, C.; McCammon, M.; McGuire, A.D.; Serreze, M. Chapter. 22: Alaska. In Climate Change Impacts in the United States: The Third National Climate Assessment; Melillo, J.M., Richmond, T.C., Yohe, G.W., Eds.; U.S. Global Change Research Program: Washington, DC, USA, 2014; pp. 514-536.

5. Huntington, H.; Callaghan, T.; Fox, S.; Krupnik, I. Matching traditional and scientific observations to detect environmental change: A discussion on arctic terrestrial ecosystems. Ambio 2004, 13, 18-23.

6. Mercer, J.; Kelman, I.; Taranis, L.; Suchet-Pearson, S. Framework for integrating indigenous and scientific knowledge for disaster risk reduction. Disasters 2010, 34, 214-239.

7. Wildcat, D.R. Introduction: Climate change and indigenous peoples in the USA. Clim. Chang. 2013, 120, 509-515.

8. Berkes, F. Sacred Ecology, 3rd ed.; Routledge: New York, NY, USA, 2012. 
9. Williams, T.; Hardison, P. Culture, law, risk and governance: Contexts of traditional knowledge in climate change adaptation. Clim. Chang. 2013, 120, 531-544.

10. Cochran, P.; Huntington, O.H.; Pungowiyi, C.; Tom, S.; Chapin III, F.S.; Huntington, H.P.; Maynard, N.G.; Trainor, S.F. Indigenous frameworks for observing and responding to climate change in Alaska. Clim. Chang. 2013, 120, 557-567.

11. Salick, J.; Byg, A. Indigenous Peoples and Climate Change; Tyndall Centre for Climate Change Research: Oxford, England, 2007.

12. Turner, N.J.; Clifton, H. "It's so different today": Climate change and indigenous lifeways in British Columbia, Canada. Glob. Environ. Chang. 2009, 19, 180-190.

13. Agrawal, A. Dismantling the divide between indigenous and scientific knowledge. Dev. Chang. 1995, 26, 413-439.

14. Krupnik, I. Watching ice and weather our way: Some lessons from yupik observations of sea ice and weather on St. Lawrence Island, Alaska. In The Earth is Faster Now: Indigenous Observations of Arctic Environmental Change; Krupnik, I., Jolly, D., Eds.; Arctic Research Consortium of the United States: Fairbanks, AK, USA, 2002; pp. 156-199.

15. Krupnik, I.; Jolly, D. The Earth is Faster Now: Indigenous Observations of Arctic Environmental Change; Arctic Research Consortium of the United States: Fairbanks, AK, USA, 2002.

16. Huntington, H.P. Arctic science: The local perspective. Nature 2011, 478, 182-183.

17. Ignatowski, J.A.; Rosales, J. Identifying the exposure of two subsistence villages in Alaska to climate change using traditional ecological knowledge. Clim. Chang. 2013, 121, 285-299.

18. Weatherhead, E.; Gearheard, S.; Barry, R.G. Changes in weather persistence: Insight from Inuit knowledge. Glob. Environ. Chang. 2010, 20, 523-528.

19. IPCC (Intergovernmental Panel on Climate Change). Climate Change 2007: Impacts, Adaptation, and Vulnerability, Contribution of Working Group II to the Fourth Assessment Report of the Intergovernmental Panel on Climate Change; Parry, M.L., Canziani, O.F., Palutikof, J.P., van der Linden, P.J., Hanson, C.E., Eds.; Cambridge University Press: Cambridge, England, 2007.

20. Nakashima, D.J.; McLean, K.G.; Thulstrup, H.D.; Castillo, A.R.; Rubis, J.T. Weathering Uncertainty: Traditional Knowledge for Climate Change Assessment and Adaptation; United Nations Educational, Scientific and Cultural Organization: Paris, France, 2012.

21. Hiwasaki, L.; Luna, E.; Syamsidik; Shaw, R. Process for integrating local and indigenous knowledge with science for hydro-meteorological disaster risk reduction and climate change adaptation in coastal and small island communities. Int. J. Disaster Risk Reduct. 2014, 10, 15-27.

22. Ford, J.D.; Pearce, T.; Gilligan, J.; Smit, B.; Oakes, J. Climate change and hazards associated with the ice use in Northern Canada. Arct. Antart. Alp. Res. 2008, 40, 127-138.

23. Eira, I.M.G.; Jaedicke, C.; Magga, O.H.; Maynard, N.G.; Vikhamar-Schuler, D.; Mathiesen, S.D. Traditional Sámi snow terminology and physical snow classification-Two ways of knowing. Cold Reg. Sci. Technol. 2013, 85, 117-130.

24. Lefale, P. Ua 'afa le Aso Stormy weather today: Traditional ecological knowledge of weather and climate. The Samoa experience. Clim. Chang. 2010, 100, 317-335.

25. Armitage, D.; Berkes, F.; Dale, A.; Kocho-Schellenberg, E.; Patton, E. Co-management and the co-production of knowledge: Learning to adapt in Canada's Arctic. Glob. Environ. Chang. 2011, 21, 995-1004. 
26. King, D.N.; Goff, J.R. Benefitting from differences in knowledge, practice and belief: Maori oral traditions and natural hazards science. Nat. Hazard. Earth Sys. 2010, 10, 1927-1940.

27. Vogel, C.; Moser, S.C.; Kasperson, R.E.; Dabelko, G.D. Linking vulnerability, adaptation, and resilience science to practice: Pathways, players, and partnerships. Glob. Environ. Chang. 2007, 17, 349-364.

28. Mercer, J.; Kelman, I.; Suchet-Pearson, S.; Lloyd, K. Integrating indigenous and scientific knowledge bases for disaster risk reduction in Papua New Guinea. Geog. Ann. 2009, 91, 157-183.

29. Pearce, T.D.; Ford, J.D.; Laidler, G.J.; Smit, B. Duerden, F. Allarut, M.; Andrachuk, M.; Baryluk, S.; Dialla, A.; Elee, P.; et al. Community collaboration and climate change research in the Canadian Arctic. Polar Res. 2009, 28, 10-27.

30. Tyler, N.J.C.; Turi, J.M.; Sundset, M.A.; StrÃ, K.; Bull, M.; Sara, M.N.; Reinert, E.; Oskal, N.; Nellemann, C.; McCarthy, J.J.; et al. Saami reindeer pastoralism under climate change: Applying a generalized framework for vulnerability studies to a sub-arctic social-ecological system. Glob. Environ. Chang. 2007, 17, 191-206.

31. Berkes, F. Epilogue: Making sense of arctic environmental change? In The Earth is Faster Now: Indigenous Observations of Arctic Environmental Change; Krupnik, I., Jolly, D., Eds.; Arctic Research Consortium of the United States: Fairbanks, AK, USA, 2002; pp. 334-350.

32. Krupnik, I.; Ray, G.C. Pacific walruses, indigenous hunters, and climate change: Bridging scientific and indigenous knowledge. Deep Sea Res. 2007, 54, 2946-2957.

33. Gearheard, S.; Pocernich, M.; Stewart, R.; Sanguy, J.; Huntington, H. Linking Inuit knowledge and meterological station observations to understand changing wind patterns at Clyde River, Nunavut. Clim. Chang. 2010, 100, 267-294.

34. Kirkby, P.; Williams, C.; Huq, S. A brief overview of Community-Based Adaptation. Available online: http://eprints.utas.edu.au/22473/1/CBA\%20brief_KirkbyWilliamsHuq_20Apr15.pdf (accessed on 10 September 2015).

35. IIED (International Institute for Environment and Development). Community-based Adaptation (CBS) Conference Archive. Available online: http://www.iied.org/community-based-adaptationcba-conference-archive (accessed on 11 June 2015).

36. IIED (International Institute for Environment and Development). Nairobi Declaration on Community-Based Adaptation to Climate Change. Available online: http://pubs.iied.org/ G03919.html (accessed on 11 June 2015).

37. Forsyth, T. Community-based adaptation: A review of past and future challenges. Clim. Chang. 2013, 4, 439-446.

38. Allen, K.M. Community-based disaster preparedness and climate adaptation: local capacity-building in the Philippines. Disasters 2006, 30, 81-101.

39. Van Alst, M.K.; Cannon, T.; Burton, I. Community level adaptation to climate change: The potential role of participatory community risk assessment. Glob. Environ. Chang. 2007, 18, 165-179.

40. Burton, I.; Bizikova, L.; Dickinson, T.; Howard, Y. Integrating adaptation into policy: Upscaling evidence from local to global. Clim. Policy 2007, 7, 371-376.

41. Travis, W.R.; Bates, B. What is climate risk management? Clim. Risk Manag. 2012, 1, 1-4. 
42. Kettle, N.P.; Dow, K.; Tuler, S.; Webler, T.; Whitehead, J.; Miller, K.M. Intergrating scientific and local knowledge to inform risk-based management approaches for climate adaptation. Clim. Risk Manag. 2014, 4, 17-31.

43. Granderson, A.A. Making sense of climate change risks and responses at the community level: A cultural-political lens. Clim. Risk Manag. 2014, 3, 55-64.

44. Hansen, J.; Sato, M.; Rued, R. Perception of climate change. P. Natl. Acad. Sci. 2012, 109, 14726-14727.

45. Borick, C.; Rabe, B. National Survey of American Public Opinion on Climate Change; Brookings Institution: Washington, DC, USA, 2011.

46. ACIA (Arctic Climate Impact Assessment). Arctic Climate Impact Assessment: Impacts of a Warming Climate; Cambridge University Press: New York, NY, USA, 2004.

47. AMAP (Arctic Monitoring and Assessment Programme). Snow, Water, Ice and Permafrost in the Arctic (SWIPA): Climate Change and the Cryosphere; Arctic Monitoring and Assessment Programme: Oslo, Norway, 2011.

48. USGCRP (United States Global Change Research Program) Global Climate Change Impacts in the United States; Cambridge University Press: New York, NY, USA, 2009.

49. Melillo, J.; Terese, T.C.; Richmond, T.C.; Yohe, G.W. Highlights of Climate Change Impacts in the United States: The Third National Climate Assessment; U.S. Global Change Research Program: Washington, DC, USA, 2014.

50. Hansen, J.; Sato, M.; Glascoe, J.; Ruedy, R. A common sense climate index: Is climate changing noticeably? P. Natl. Acad. Sci. 1998, 95, 4113-4120.

51. Olsen, M.S.; Callaghan, T.V.; Reist, J.D.; Reiersen, L.O.; Dahl-Jensen, D.; Grangskog, M.A.; Goodison, B.; Hovelsrud, G.K.; Johansson, M.; Kallenborn, R.; et al. The changing arctic cryosphere and likely consequences: An overview. Ambio 2011, 40, 111-118.

52. Macchi, M.; Oveido, G.; Gotheil, S.; Cross, K.; Boedhihartono, A.; Wolfangel, C.; Howell, M. Indigenous and Traditional Peoples and Climate Change; International Union for the Conservation of Nature Issues Paper: Gland, Switzerland, 2008.

53. Reo, N.J.; Parker, A.K. Rethinking colonialism to prepare for the impacts of rapid environmental change. Clim. Chang. 2013, 120, 671-682.

54. Whyte, K.P. Justice forward: Tribes, climate adaptation and responsibility. Clim. Chang. 2013, 120, $517-530$.

55. Himes-Cornell, A.; Kasperski, S. Assessing climate change vulnerability in Alaska's fishing communities. Fish. Res. 2015, 162, 1-11.

56. Arctic Council. Arctic Resilience Interim Report 2013; Stockholm Environment Institute and Stockholm Resilience Centre: Stockholm, Sweden, 2013.

57. United States Government Accountability Office. Alaska Native Villages: Limited Progress Has Been Made on Relocating Villages Threatened by Flooding and Erosion, GAO-09-551; United States Government Accountability Office: Washington, DC, USA, 2009.

58. United States Army Corps of Engineers. Alaska Baseline Erosion Assessment: Study Findings and Technical Report; USACE Alaska Division: Elmendorf Air Force Base, AK, USA, 2009.

59. Immediate Action Work Group. Recommendations to the Governor's Subcabinet on Climate Change; The State of Alaska: Juneau, AK, USA, 2009. 
60. United Nations. United Nations Declaration on the Rights of Indigenous Peoples. Available online: http://www.un.org/esa/socdev/unpfii/documents/DRIPS_en.pdf (accessed on 9 June 2015).

61. Fall, J.A.; Braem, N.S.; Brown, C.L.; Hutchinson-Scarbough, L.B.; Kaster, D.S.; Krieg, T.M. Continuity and change in subsistence harvests in five Bering Sea communities: Akutan, Emmonak, Savoonga, St. Paul, Togiak. Deep Sea Res. 2013, 94, 274-291.

62. United States Census Bureau. Population Finder. Available online: http://www.census.gov/ popfinder/ (accessed on 11 June 2010).

63. United States Census Bureau. American FactFinder. Available online: http://factfinder.census.gov/ faces/nav/jsf/pages/index.xhtml (accessed 5 September 2015).

64. R Core Team. $R$ : A language and environment for statistical computing; R Foundation for Statistical Computing: Vienna, Austria, 2014. Available online: http://www.R-project.org/ (accessed on 5 June 2015).

65. Meyer, D.; Zeileis, A.; Hornik, K. Visualizing Categorical Data [VCD], R package version 1.4-1; R Foundation for Statistical Computing: Vienna, Austria, 2015.

66. Kinsman, N.E.M.; DeRaps, M.R. Coastal Hazard Field Investigations in Response to the November 2011 Bering Sea Storm, Norton Sound, Alaska. Report of Investigations 2012-2; State of Alaska Department of Natural Resources, Division of Geological \& Geophysical Surveys: Fairbanks, AK, USA, 2012.

67. Johnson, T.; Gray, G. Shaktoolik, Alaska: Climate Change Adaptation for an At-Risk Community; National Sea Grant College Program: Fairbanks, AK, USA, 2014.

68. United States Army Corps of Engineers. Shaktoolik Coastal Flooding Analysis; United States Army Corps of Engineers: Anchorage, AK, USA, 2011.

69. Oozeva, C.; Noongwook, C.; Noongwook, G.; Alowa, C.; Krupnik, I. Watching Ice and Weather Our Way; Arctic Studies Center, Smithsonian Institution: Washington, DC, USA, 2004.

70. Fienup-Riordan, A.; Rearden, A. Ellavut: Our Yup'ik World \& Weather; University of Washington Press: Seattle, WA, USA, 2012.

71. Nilsson, C.; Polvi, L.E.; Lind, L. Extreme events in streams and rivers in arctic and subarctic regions in an uncertain future. Freshw. Biol. 2015, doi:10.1111/fwb.12477.

72. Alaska Department of Labor and Workforce Development, Research and Analysis Section. Alaska Population Overview: 2013; Alaska Department of Labor and Workforce Development: Anchorage, AK, USA, 2015.

73. Salick, J.; Ross, N. Traditional peoples and climate change. Glob. Environ. Chang. 2009, 19, 137-139.

(C) 2015 by the authors; licensee MDPI, Basel, Switzerland. This article is an open access article distributed under the terms and conditions of the Creative Commons Attribution license (http://creativecommons.org/licenses/by/4.0/). 